\title{
THE UNIVERSITY OF MINNESOTA
}

\section{GRADUATE SCHOOL}

\author{
Report \\ of
}

Committee on Thesis

The undersigned, acting as a Committee of the Graduate School, have read tho accompanying thesis submitted by Joseph Valasek for the degree of haster of Sclence They approve it as a thesis meeting the requirements of the Graduate School of the University of Minnesota, and recommend that it be accepted in partial fulfillment of the requirements for the degree of Master of Science.
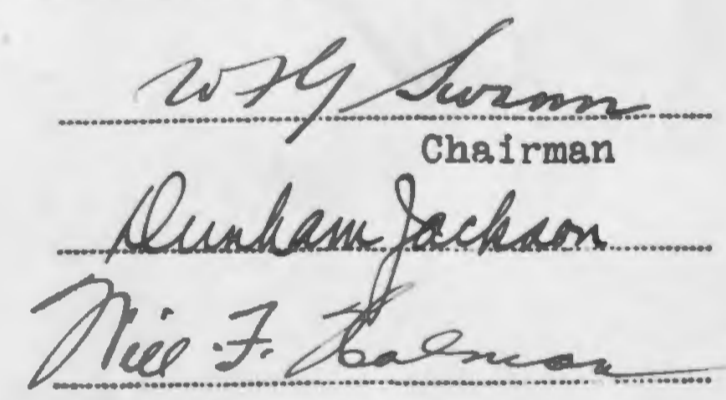

Jan 1 1. $19 \sum^{20}$ 
THE UNIVERSITY OF MINNESOTA

GRADUATE SCHOOL

Report

of

Committee on Examination

This is to certify that we the

undersigned, as a committee of the Graduate

School, have given Joseph Valagek

final oral examination for the degree of

Master of science. We recommend that the

degree of Master of Science be conferred upon the candidate.

Minneapolis, Minnesota

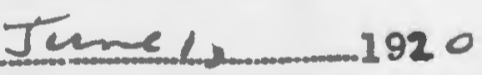

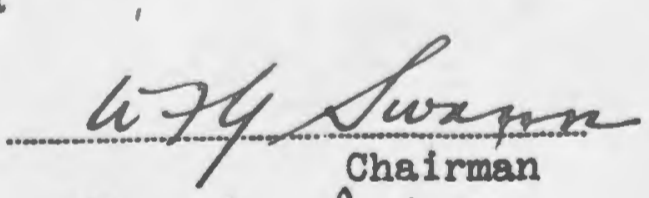

Sunken Jackson

Mien. tasman,

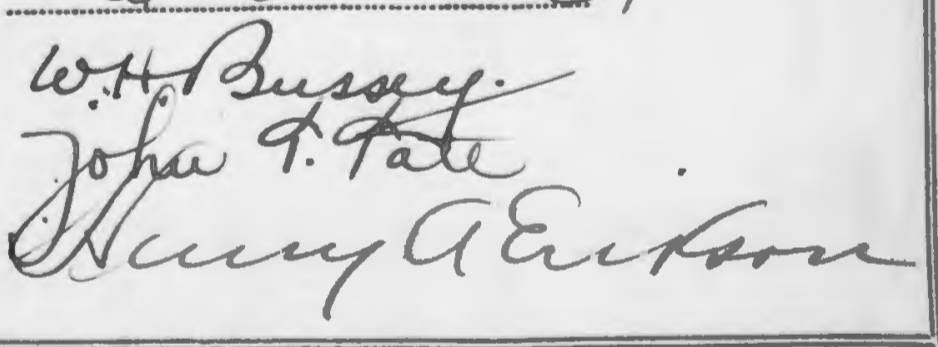




\section{PIEZO-ELECTRIC AND ALLIED PHENONENA}

\section{IN ROCHELLE SALT}

A Thesis submitted to the Faculty of the Graduate School

$$
\text { of the }
$$

University of Kinnesota

by

Joseph Valasek

in

partial furlfillment of the requirements for the degree of Master of Science in Physics. June 1920. 
CONTENTS.

I. Introduction

(a) Fundamental Phenomena

(b) Recent work bearing on this problem 4-5

II. An Explanation of the Anomalies Recently Observed

III. Experimental Verification

(a) Apparatus and Technique

(b) The Observations

IV. Conolusion

v. Summary

V1. Bibllography pp $1-5$

$1-4$

$6-8$

$8-12$

$8-10$

$10-18$

$13-14$

$14-15$

16 


\section{INTRODUCTION}

(a) The Fundamental Phenomena.

In 1880 , the brothers J. \& P. Curle observed that a plate cut from crystalline quartz produced accumulations of electric charges on opposite faces when subjected to a mechanical force. This electro-elastic property they termed plezo-electricity. It was soon found that many other crystals likewise exhibited this interesting phenomenon, and it was shown that there also existed a converse effect, in virtue of which, a piezo-electrio substance ouffered a deformation when placed in an electric fleld. I'nis correlation betreen force and electric field, at least as far as deformation is concerned, is worthy of note.

of the thirty-two classes into which crystalline matter is divided, according to the nature of thelr symmetry, there exists in twenty, at least one axis, which is characterized by different sets of faces on 1ts opposite ends. Crystals which possess this type of aeymmetry all exhibit piezo-electric actirity to a certain degree. In these crystals, there are one or more axes at the onds of which free charges are produced when the cryetal is deformed by mechanical force in some definite ray. These axes are called the piezo-electric axes.

As a result of investigations on a flat quartz plate, cut from the crystal in such a way that its faces are normal to a piezo-electric axis, P. Curie formulated the following statemente:

(1) Equal and opposite charges are developed on the opposite ends of a piezo-electric axis. 
(3) The effect produced by a compression is equal and opposite to that produced by an equal tension.

(3) Force applied perpendicular to the collecting plates produces a quantity of eleotricity which is directly proportional to the total force and 18 independent of the area of the face orer which it is applied. This relation is expressed by the formula $q=\Delta^{-} F$, where $q$ is the quantity in electrostatic units, $F$ is the force in dynes and $\Delta$ is a constant found by P.Curie to be equal to $6.33 \times 10^{-8}$ e.s.u. per dyne for a quartz plate oriented as described.

(4) For a force applied parallel to the collecting plates, 1.e. On the ends of the crystal section, the charge is expressed by the formula $q=\Delta n \cdot \frac{1}{d}$ where $/ 1$ s the length of the cryetal in the direction of the force and $d$ is the thickness, (1.e. the distance between the electrodes) and $\Delta$ is the same constant as above.

A simple qualitative explanation of the piezo-olectric effect is given by Lord Kelvin. He assumes the molecules of all piezoelectric crystals to be permanent electric doublets, and that the effect of a force is to change the molecular moment per unit rolume by altering the distances between the molecules. This, he shows, produces free ourface charges on the faces of the cryatal. Ihis theory is generally accepted and although it leads to no quantitative results, it gives a clear picture of the piezo-electric mechanism.

1. Volgt ${ }^{*}$, however, gives a theory which goes much farther then Thomson's. By means of thermodynamic reasoning he shows 
that the plezoelectric response on faces normal to the crystallographic axes 1,2 , and $3(x, y, z)$ bears a linear relation to the six elementary stresser, namely the three components of dilatation $X_{x}, Y_{y}, Z_{z}$ and the three components of shear $Y_{z}, Z_{x}, X_{y}$. This relation is expressed by the formulae:

$$
\begin{aligned}
& -p_{1}=\delta_{11} X_{x}+\delta_{12} Y_{y}+\delta_{13} z_{z}+\delta_{14} Y_{z}+\delta_{15} z_{x}+\delta_{16} X_{y} \\
& -p_{2}=\delta_{21} X_{x}+\delta_{22} Y_{y}+\delta_{23} z_{z}+\delta_{2 y} Y_{z}+\delta_{25} Z_{x}+\delta_{26} X_{y} \\
& -p_{3}=\delta_{31} X_{x}+\delta_{32} Y_{y}+\delta_{33} z_{z}+\delta_{31} Y_{z}+\delta_{35} z_{x}+\delta_{36} X_{y} .
\end{aligned}
$$

The eighteen constante $\delta_{i x}$ are termed the piezoelectric moduli. In every case except in that of the triclinic hemihedric group, which has the highest degree of asymmetry, the number of these constants is materially reduced. For example quartz has only Iive of these moduli differing from zero and these are connected by simple algebraic relations, leaving only two independent. Rochelle salt, in which we are especially interested has only three constants, its piezoelectric action being described by the relations:

$$
\begin{aligned}
& -p_{1}=\delta_{14} Y_{2} \\
& -p_{2}=\delta_{25} Z_{x} \\
& -p_{3}=\delta_{36} x_{y}
\end{aligned}
$$

From these equations it appears immediately that Rochelle salt is active only with respect to the three components of shear $Y_{1}, \bar{Z}_{x}, X_{y}$ about the crystallographic axes $1,2,3$ which are usually denoted $a s$ the $\dot{a}, \bar{b}$ and $c^{\prime}$ axps. The three constants in these equations have been determined experimentally by Pockels who gives the following values:

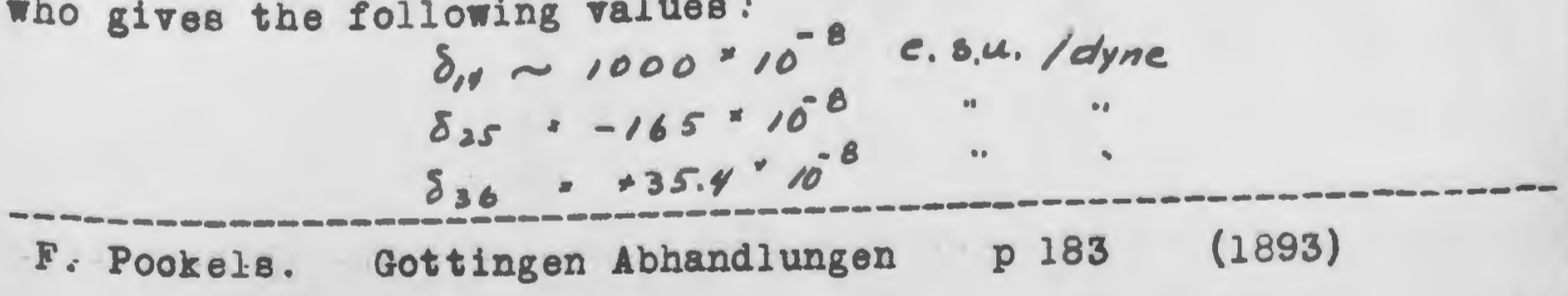


He accompanies the value of $\delta_{, 4}$ however with the remark that it is merely a lower limit of the values observed. This makes Rochelle salt, properiy oriented, the most piezoelectrioally active substance known, being more than 150 times as active as quartz.

(b) Recent Work Bearing on this Problem.

This great sensitivity of Rochelle salt has led to many attempts to utilize its action in a practical way. Its properties would appear to be valuable whenever it is desired to detect or translate a small mechanical efiect into an electrical eftect which can then be recorded or amplified in the usual way, it desired. Some very recent work is this direotion is excellently reviened by H. O. Nood in his report of Narch 1919. The conclusion arrived at is that Rochelle salt is anomalous in its behavior and that it does not follow the simple theory outilined above except in a very general way. The observations leading up to this research will accordingly be brierly reviewed.

It has been observed by $\mathrm{Cady}^{\circ}$ and others that crystal plates of Rochelle salt, orlented in such a way as to exhibit the maximum effect, do not give a linear relation between force and piesoelectric response as measured by a ballistic galvanometer. The response, instead, increases more rapidy with the load for small Iorces, while as the load is increased, the effect increases at a +ess rapid rate. Curves, obtained by the writer, showing this effect are given in Fig. 1. In the curves obtained by Cady the * H.O. Wood - Captain U.S.Ingineers - Report - March 1919.

- Cady. Report to National Research Council. May 1918. 
$\frac{4}{8}$

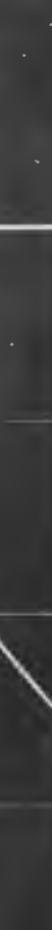

20 
deviation from a linear relationship is mach more marked. There Is moreover an effect of fatigue and even paralysis at high loads. The response to pressure has been observed deminish $600 / 0$ in four minutes, due to fatigue. Temperature is another important factor. The sensitiveness of a crystal diminishes 50 o/o for a Ise in temperature from $30^{\circ} \mathrm{C}$ to $35^{\circ} \mathrm{C}$ and decreases 60 o/o more for a further 1180 of $5^{\circ} \mathrm{C}$. It has also been observed that humidity affects the results in a remarkable way. Although the crystal is more sensitive in a moist atmosphere, the experimental results are apt to be inconsistent unless the crystal surfaces are thoroughly dry.

Experiments where made by J.A.Anderson ${ }^{*}$ on the behavior of Rochelle salt crystal plates used both as condensers and as piezoelectrio generators. He observed that the ballistic galvanometer charge and discharge throws of the crystal used as a condenser nere unequal for tields of one sign, but that they were equal and smaller for flelds of opposite sign. He explains his observations on the sosumption of a superposed electrostriction effect. He also gives a set of ourves showing the result of applying a steady pressure to the oryetal condenser and then observing the charging throws. These curves have a maximum for tields applied In one direction and fall off gradually for Iields applied in the opposite way. These results seemed, at that time, to be unexplain\# able. 
II. AN EXPLANATION OF THE ANOMALIES RECENTLY OBSERVED.

The object of this research was to study the erratic behavior described above and to formulate, is possible, the necessar. extensions of the simple theory to cover these deviations. It was ouggested by Dr. W. F. G. Swann that the first set of Anderson/s curves just discussed might be due to a hysteresis in the crystal. This question was accordingly the pirst to be taken up and investigated.

On the doublet theory of dielectric action an electric field produces a state of polarization in the medium. One may picture this to himself as a slight displacement of the electronic orbits of each molecule with respect to the central positirely charged nucleus. The amount of the resulting electric moment per cubic centimeter is defined as the polarization of the dielectric and is usualiy denoted by $P$. The surface density of electric charge produced by this polarization is likewise equal to P. If E ropresents the electrio intensity and $D$ the dielectrio displacement, then the relation between $D, E$ and $P$ is expressed by

$$
D=E+4 \pi P
$$

The charge $q$ on the plates of a parallel plate condenser is then in general

$$
q=\frac{x S}{4 \pi d} \cdot V=\frac{S}{4 \pi}(E+4 \pi P)
$$

where the area of the plate 18 denoted bJ $S$ and the distance between the electrodes by $d$. Since the charge and discharge throws of the balliatic galvanometer are proportional to the alteration in the quantity of eleotriolty in the condenser, they will give a measure of the change in the dielectric displacement $D$. 
The case of magnetism is exactly analogous to that of a dielectric. If $B$ represents the magnetic induction, $H$ the field strength and I the intensity of magnetization, the relation between them is given by the formula $B=H+4 \pi I$. In this magnetic case it is a well known fact that $B$ shows a "saturation" as H increases, and, moreover, that B goes through a hysteresis cycle for variations of $\mathrm{H}$.

Because of the parallelism between dielectrio action and magnetism, it appears at once that the ungymmetrical charge and discharge throws which were observed by Anderson can be explained by a hysteresis in $P$ (and consequently in $D$ ). It this hysteresis loop is not symmetrical with respect to the origin, $P$ will be nearer "saturation" for filelds in the opposite direction to that applying above, and hence the throws would be smaller and more nearly equal. Curves, haring these general characteristios have been obtained with iron as well as with Rochelle Balt. Tho displacement with respect to the origin, postulated above, woula mean that there is a polarization in the natural orystal. This polarization may be regarded as being identical with that which is required by Thomson's theory or piezo-electricity. A real test of this explanation would consist in attempting to obtain a nysteresis loop of D versus $k$ for Rochelle salt. An Interesting teature of this curve woula be the diplacement from the origin, giving the molecular electric moment of the eryatal in its natural state.

The curves of $D$ versus $\mathrm{E}$ as already noted, are not on $\perp \mathrm{y}$ unsymmetrical but they also approach saturation as $\mathrm{E}$ inoreases. 
Thus if the eurve fe in plottad againat $\mathrm{z}$ thore will be $\mathrm{s}$ naximan for some value of $\mathbf{E}$, eorreaponding to the point of moat

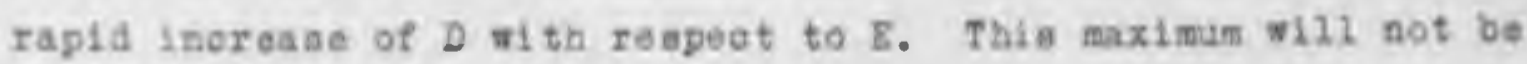
at zero, but at some $\mathrm{E}$ with a definita siga, beeauas of the asyasotry of the firat eurve. It bas slready been remarkod that the effeots of foroe and applied oleotric fieid are equiriont in produeing a piozoelootrie deformation of the dryatal. To the extent then that the foree and field may be oonelderod an equirslont in affecting the piezoeleotzic momsnt, we may expoot that the

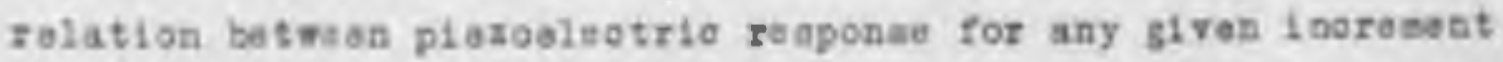
of force (ie $\frac{\Delta D}{\Delta t}$ ) and the fleld $\mathrm{E}$ to be of the sane nature as the relation of $\frac{\partial \partial}{\partial E}$ and $\mathrm{z}$. Suoh man indeed found to be the ease.

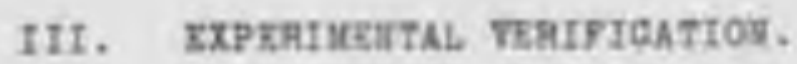

(a) Apparatus asd Taotmiquo.

In arder to teht thee deduetiono an apparatas wan conetruatad mieh would allor a mimiltansoue zogulation or the varioun factoro antoring into the probles, an proviouly diecuaad. Thoos faotoro ure sempersture, applied foroe, olnotrie field, and mumidtyl The variatsose in tho eleatrio ebarge on the eleotrodea of the eryotal were meaured by a Leede asd Northrup bigh wensitivity balliatie gal vasometer.

The oryatal and all dirootly zonneoted parte mare fneloned In a glare contaipor an obows la the aeodepanying aketeh. Fig a. This allored the apparatuo to be eraguated or to be asaled off ais ticht, whenerer deairod, in order to preaerva a conatant 


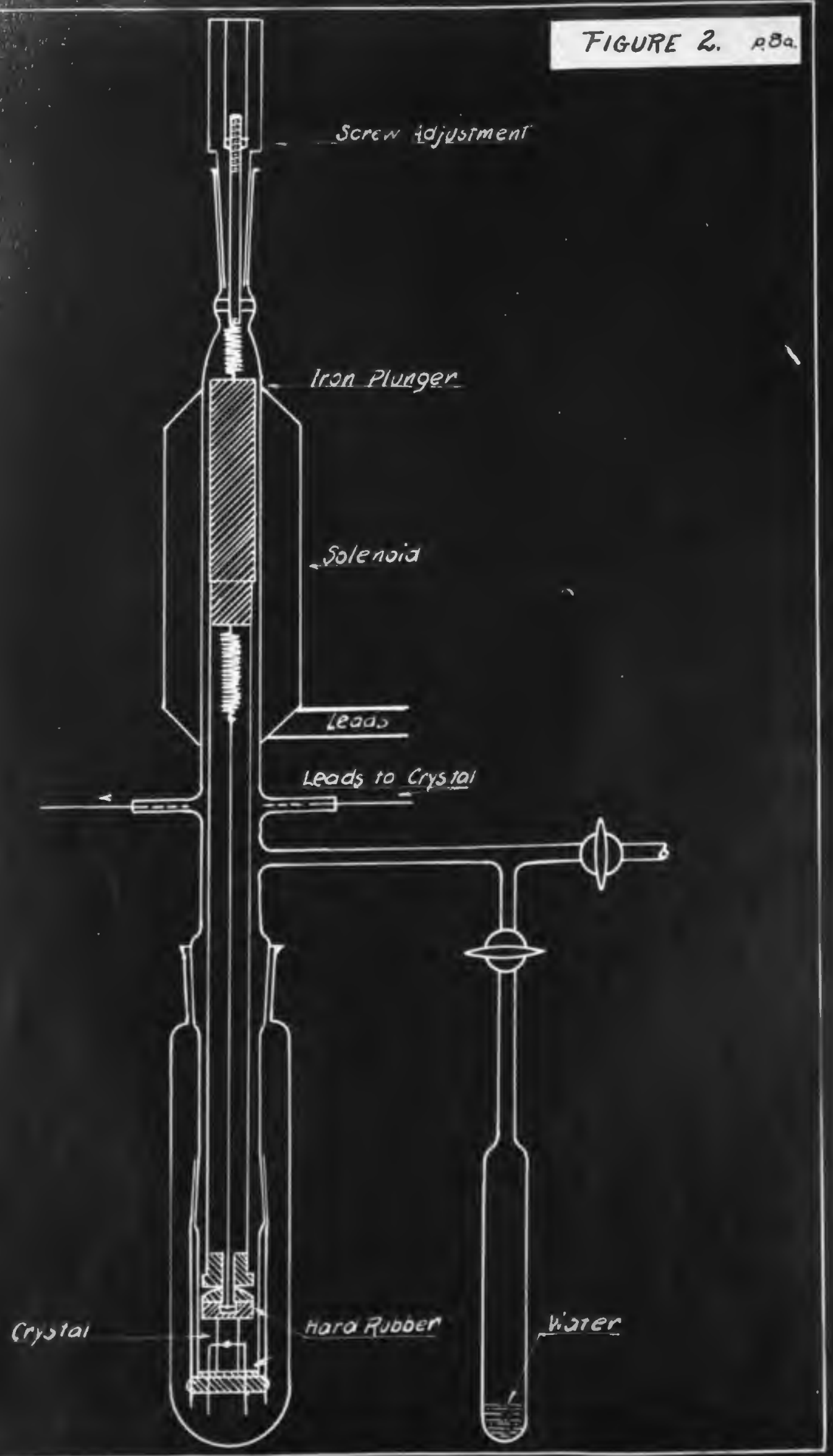


atmospheric condition.

The force mechanism consisted of a solenoid with an iron plunger at the end of a glass tube, which transmitted the compression to the cryetal which was mounted on a hard rubber block directly below. The weight of the plunger and the effect of residual magnetism was compensated by a spring and scre mechanism which could be adjusted by means of a ground glass tap. These adjustments could be made at any time when the apparatus was sealed. The end of the glass rod was provided with a universal jolnt attachment made of hard rubber, which served to distribute the force uniformly orer the ends of the crystal.

For regulating the humidity a bulb containing some water was attached to the body of the glass container. This bulb was immersed in a dewar flask which was ueually filled with ice, thus giving a constant absolute humidity in the apparatus. The lower portion of the chamber contalning the orystal was immersed well into a large dewar jar which provided beat insulation and also served as a means for the regulation of temperature by means of water baths and freezing mixtures. The temperatures were measured by two copper constantan thermocouples whose junotions were soldered to the tinioil electrodes on the faces of the crystal. Two or the thermocouple wires also served as connections to the ballistio galvanomuter and to the high roltage potentiometer arrangement which regulated the applied electric field. This consisted of a resistance of ten megohms, subdivided into ten equal parts. The various subdivisions were connected to a commutating switch and to the orystal and galvanometer as shown in Fig. 3 . The working electromotive force was usually 800 volts 80 that the potential 


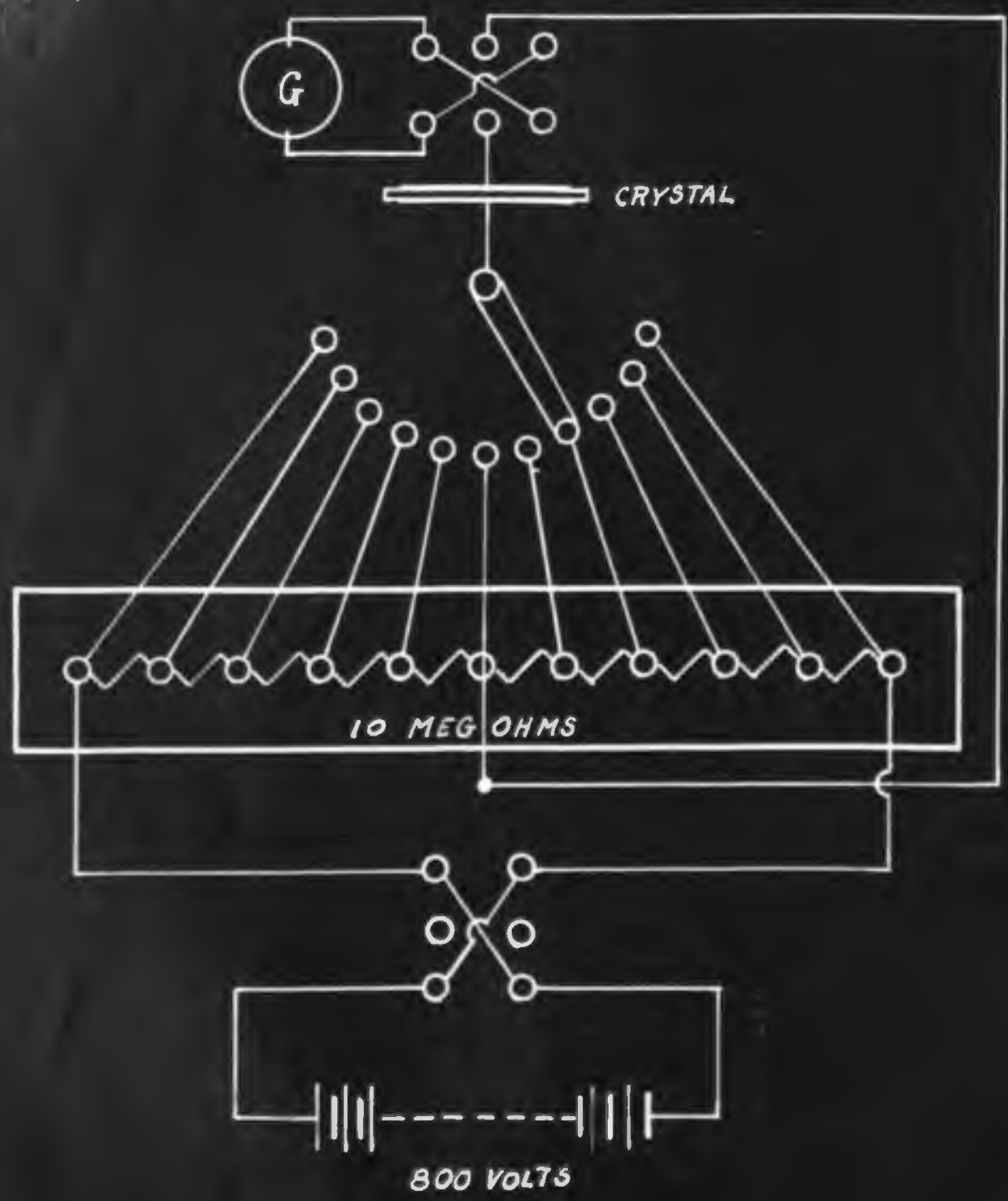


applied on the crystal could be varied from +400 to -400 rolts in steps of 80 volts each. The potentials used were measured by an electrostatlo voltmeter after each set of observations. The orystal plates used were cut from a 100 gram cryetal of Rochelle ealt which was grom and furalshed by the ceneral rlectric to whom the a thor wishes to express wis appreciation.

Company/A The plates were out by a wet thread operating over two in the mamiere described cylody pulleys and kept molet by running through a buoket of water, The faces were dressed down and smoothened by a molst plece of ground 8lass. The orientation of the faces was such as would give the the daxis maximum response. The faces were, accordingly, perpendioular to the edges making angles of $45^{\circ}$ with the $\bar{b}$ and $c^{\prime}$ axes, Ilgure 4 shors the various stages in the preparation of such a crjetal plate. Compreseing the ands of the section would accordingly result in a shear in the $\bar{b}$ and $c^{\prime}$ directions ( $Y_{z}$ after Voigt). since the shears $Z_{x}$ and $X_{y}$ ranish for a uniformly stressed erjatal of this orientation, we are left with the effect due to $Y_{t}$ alone, namely

$$
-p_{1}=S_{i,} \gamma_{2}
$$

The charge densitios on the tinfoll plateo cemented with obellac to the erystal faces are accordingly equal to and if wo let $f$ denote the longth, of the width and $d$ the thickness of the section, the relation between the total oharge $q$ and the total force on the end of the eryatal ( $F$ ) will be given by

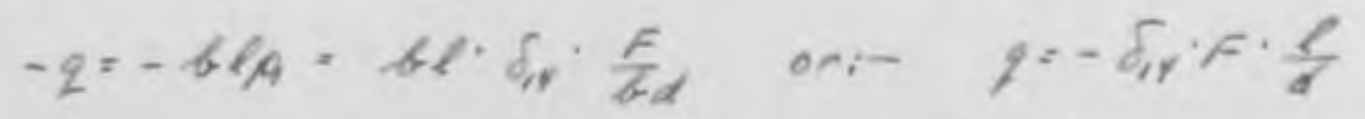

which le 1dentical with P. Curies formula with $\Delta$ replaced by ito equivalent $-5 / f$. Since the relation betwe en piezoelectric response and pressure is not a linear one in the case of Rochelle salt, $\delta_{14}$ w11 not be constant but $w 1$ II be in general some function of 5 . 


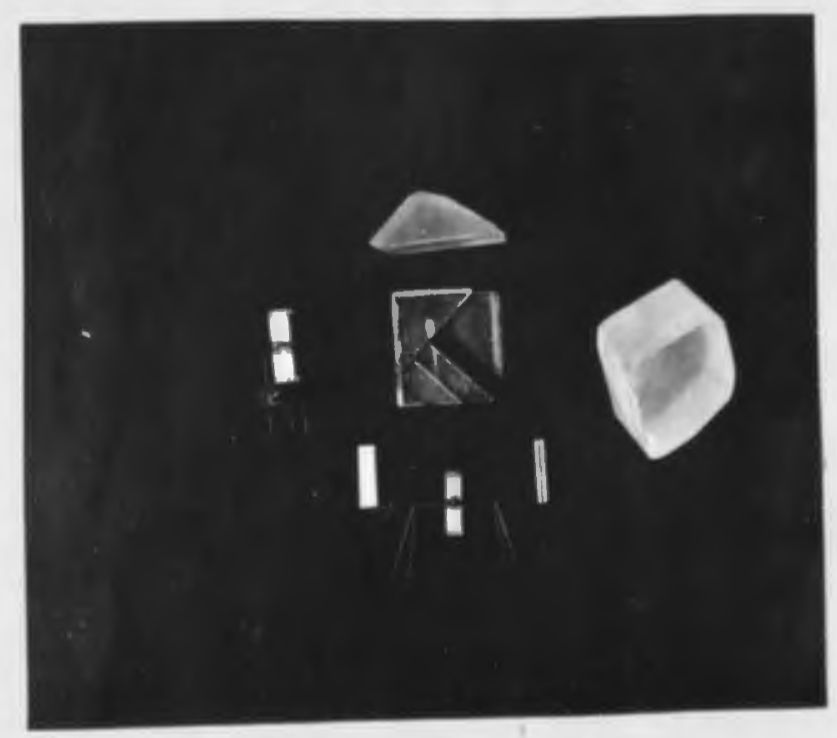

FIgUTE 4

Preparation of Cnstal Plates. 


\section{(b) The Observations.}

The behavior of the crystal as a condenser was first investigated and the conclusions as to a hysteresis in $D$ were verified. Measurements of D for cycliog changes in $E$ gave typioal hysteresis loops. They were, moreover, unsymmetrical as was to be expected if the crystal had a natural polarization. The exact character of the loop was found to depend on molsture and temperature conditions of the crystal. Figure 5 shows the results of observations at a temperature of $33^{\circ} \mathrm{C}$ and a relative humidity of $30 \mathrm{o} / \mathrm{o}$ Figure 6 gives a loop obtained at $0^{\circ} \mathrm{C}$ with the surfaces of the crystal thoroughly dried. The plate had been kept at this temperature and under cover with phosphorus pentoxide for fifteen hours before these observations were made. After twenty four hours more under these conditions there was practioally no piezoelectric activity and very little hysteresis, apparently caused by excessive dryness.

It was also soon apparent that the response to pressure showed a hysteresis with respect to ohanges in temperature, when the absolute humidity was kept constant by the method described. This appears to be due to a change in the molsture content of the crystal which then alters 1ts piezo-electric properties. That such variations in molsture occur was shown by reeping two crystal plates in molst and dry atmospheres respectively and by occasionall weighing them. The changes in weight during the first four days amounted to over $5 \% / 0$. These variations in molsture content at any temperature are relatively slow so that it requires several daye for the approach of an equilibrium molsture condition, which 
undoubtedly depends on the temperature. Such a variation appears to be the most probable cause of the temperature hysteresis loop which was observed.

Phosphorus pentoxide 18 too streng a drying agent to use in experiments with Rochelle salt, as it is oufficiently porerful to completely dehydrate the crystal after several weeks. This naturally causes it to lose its activity and it may even split open, as was observed in one case.

Curves showing the relation between electric field and piezoelectric response were obtained for a number of values of applied force. All of these curves show a maximum for an applied field of a certain sign, while they fall off gradually in the opposite direction in conformity with previous conclusions. These curves are reproduced in $51 \mathrm{~g} .7$.

Anderson has obtained a set of ourves somewhat similar in character by observations on the charge of the crystal condenser when under pressure. The results, the explanation of whiob he finds so difficult, may likewise be attributed to the equiralence of force and dlectric field in producing a change in the polarization of the cryetal. Since the curve of $D$ versus $F$ approaches saturation in both directions, the derived curve $\frac{\partial P}{\partial F}$ will have a maximum somewhere, and since $\Delta D$ corresponding to a given change in electric field $\Delta E$, will have the same characteristics as a $\triangle D$ produced by a $\Delta f$, , it will also have a maximum dieplaced with respect to the origin. 


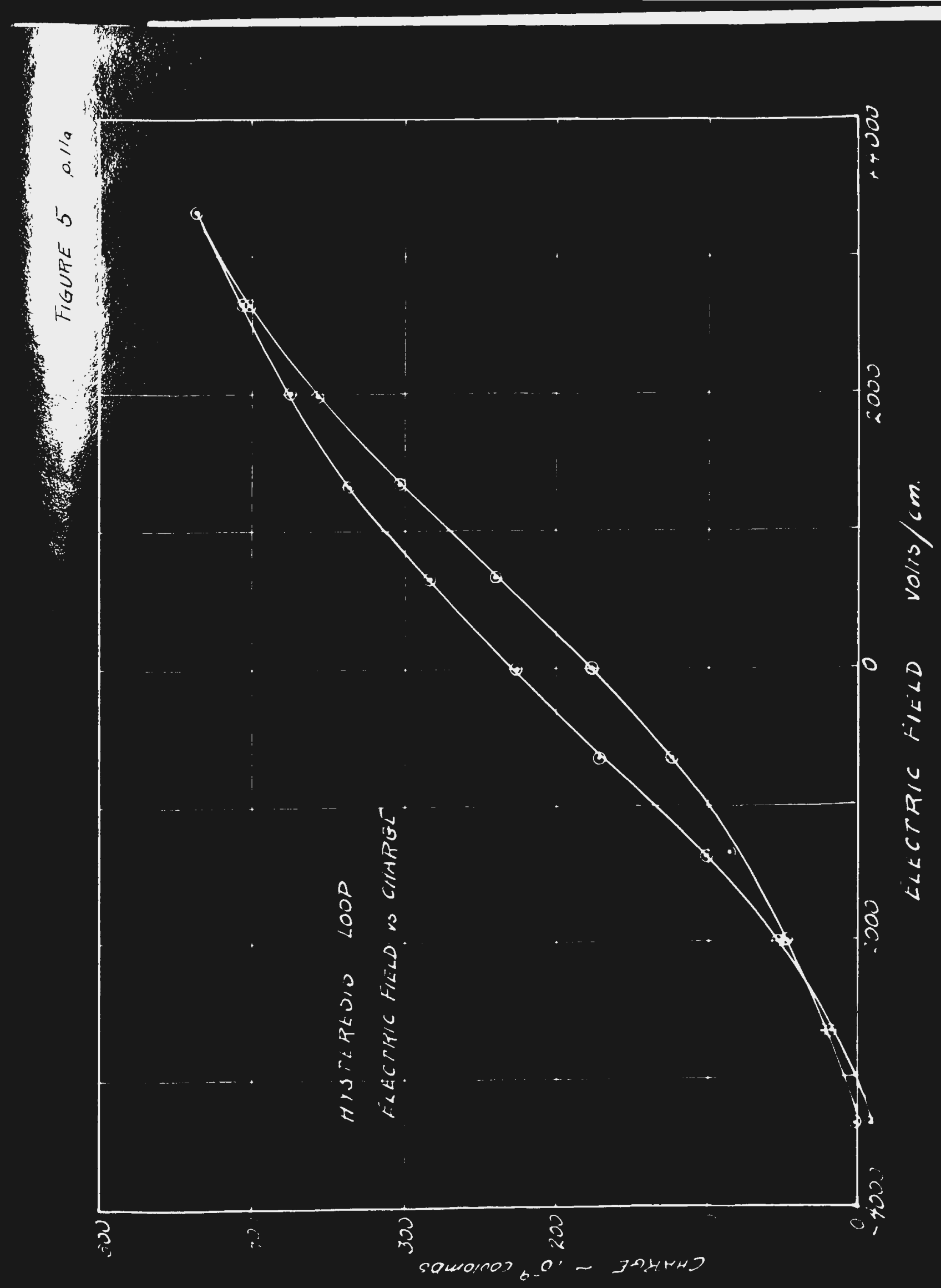




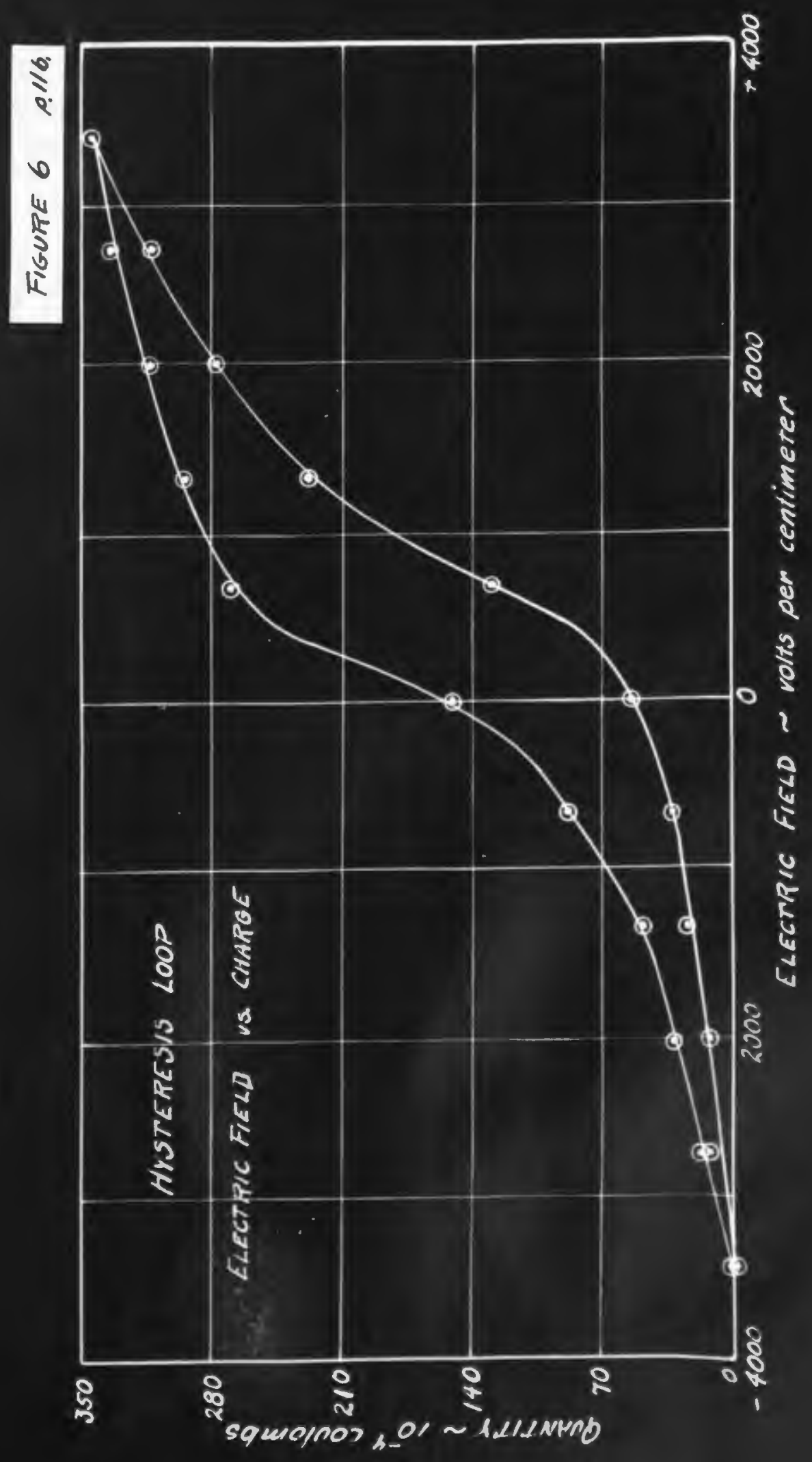




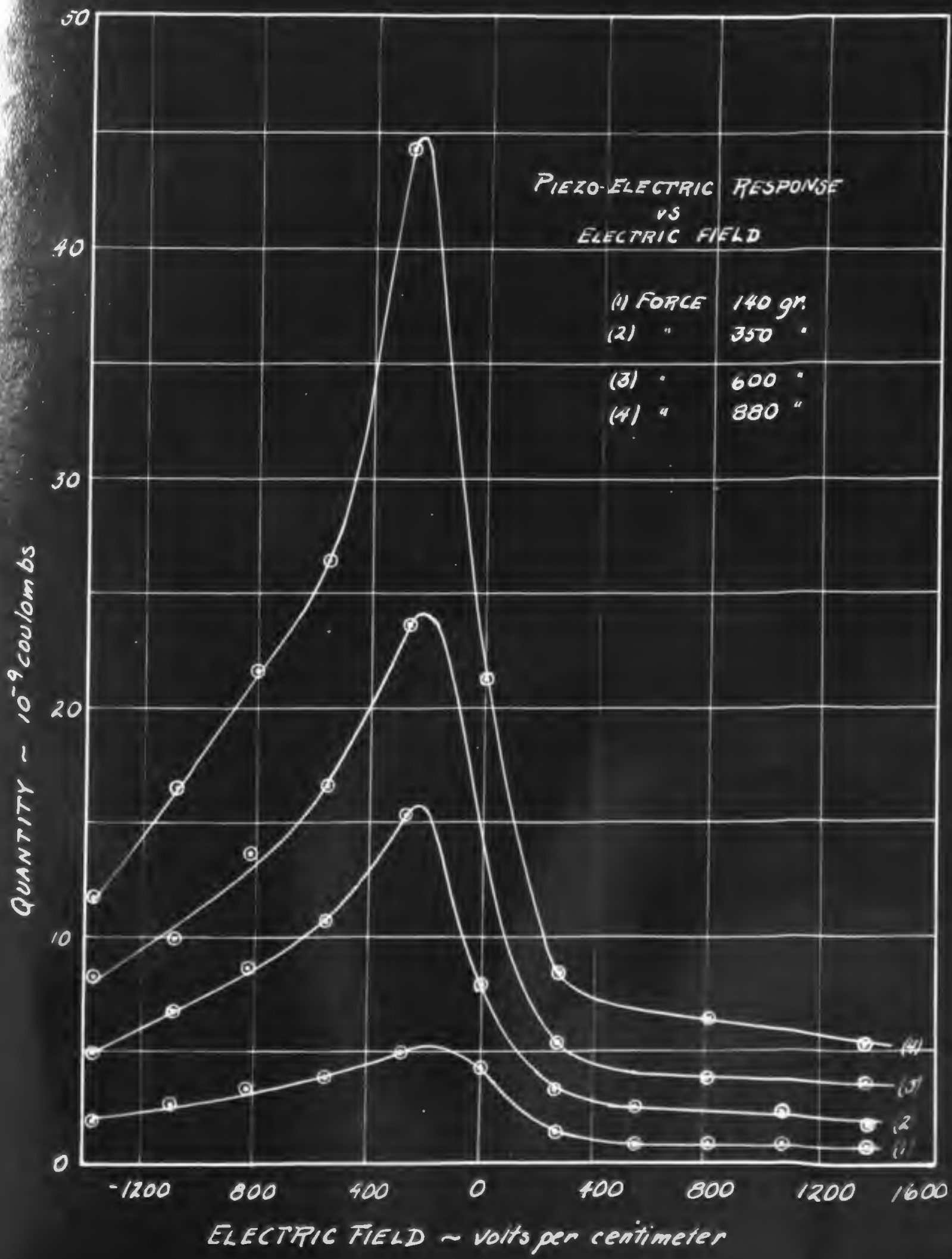


IV. CONGLUSION.

From the observations given, the dielectric, and some of the plezoelectrio constants of Rochelle salt may be calculated. The values are markedly dependent on the temperature and humidity, on the time exposed to these conditions and also on the electrical and mechanical treatment of the cryetal just preceding the observations. Accordingly, no accurate figures can be given, since the procise interrelations of these rariables is as yet unknown. The order of magnitude of the effects may however be obtained.

From the asymmetry of the hysteresis loops, the natural molecular electric moment was found to be $16,9.5 .4 . \mathrm{cm}^{2}$ at a temperature of $33^{\circ} \mathrm{C}$ and a relative humidity of $30 \mathrm{o} / 0$. It was found to have inoreased to 85. e.5.4. $/ \mathrm{min}^{2}$ at $0^{\circ} \mathrm{C}$ and in a very dry atmosphere lover $P_{2} O_{5}$ for 15 hours).

The dielectric constant showed extremely large variations under the different conditions. The lowest value observed was 46 and the highest was 560. Cady gives a value of 80 and remarks that the dielectrio "oonstant" of Rochelle salt does not appear to be constant by any means. The greatest rariation obserred was $\mathbf{w t h}$ respect to the applied field under certain conditions

The piezoelectric constant calculated from that portion of the force versus response curve which lo stralght and which is also the steepeat portion (Jig. 1) gives $8.85 * 10^{-5} \frac{\mathrm{Cs}}{\mathrm{dy}} \mathrm{m}$. Ior the value of $\delta_{\text {,y }}$ at a temperature of $23^{\circ} \mathrm{C}$ and a relative humidity of $30 \% / 0$, and $18.0 \times 10^{-5 \frac{0 . q u}{d y m e}}$ at $0^{\circ} \mathrm{C}$ and a dry condition (over $P_{2} C_{5}$ - 15 hours) Cady has previously assigned a range of 3.4 to $0 . \times 10^{-5} \frac{\text { e.s. }}{d y n e}$ for this constant. 
There 13, of courae, mueh work still to be done on thle problem. A syatematio study ahould f1rat bo made of the effecto of humidity, temperature and preamure on the plezoelectrio and dielectrio properties of Rochelle salt. It would also be Interouting to learn wether the ohanges in plezosibetric response under different conditions may be traced to ohanges in the elasticity of the cryotal. Dr. 8wann has also suggested that $x$-Ray spectrographe of the erystal in action would probably reveal some intere日ting information beoause of the rery high dieleotric conatant, which would lavolve largo atomic deformations. A study of the exaot effect of enfface moloture on the plezoelectric offect seems to offer some interesting posaibilities. In aome савев the reaponse has been observed to diminioh 50 o/0 in threa minutes after decrealing the humidity of the als in the apparatus. The moleture content inside the oxyotal can bardly change so rapidly. This suggesta a surface molsture piezoelectr.c effect which would appear to play an $f$ mportant part in the actIvity of Roohelle galt.

$$
\text { V. BUNUARY. }
$$

The reaults of this reearoh msy be briofiy aumbarized as

\section{followa :}

(1) A parallelism 1 a shown to exiet between the action of Rochelle salt as a dielectrio and of Iron as a forromagnet ic oubstane. Ilysteresis loopo of dieleotric dioplacement rersus electrio intenaity are obtained.

(3) It is shown that piezoelectric response showe a hysteresis with temperature at a constant aosolute husidity. 
(3) The effects of pressure and applied electric field are shown to be equivalent, to a certain degres, in producing a change in the piero-electric moment. Curves giving the relation between piezo-electric response and applied field are presented. 
VI. BIBLIOGRPHY. (References consulted)

H. O. Wood: Captain U.S.Ingineers. Report, March 1919.

J. A. Anderson: Report to National Research Council March 1918 April 1918.

W. G. Cady: Report to Nat1onal Research Counc11, May 1918. Winkelmann: Handbuch. Vol 3, p 535. Breslau (1891) Poynting and Thomson: Electricity and Magnetism, p I\&8. London (1914)

P. Curie: Oeurres. p 33. Paris (1908)

wiedemann: Blektricität

4 p 1381 Braunschweig (1885)

Volgt: Lehrbuch der Kryetallphyeik, p 801. Leipzig (1906) Voigt: Annalen der Phyoir. V 18, p $433-48$ (1915) Rôntgen: Innalen der Phyeik. V 35 p 737 ( 1914 ) ron Schreidler: Annal on der Physik. V 24 T11 (1907) Nicholson: Proo. A.I.E.E. Vol. 38 p 1315. (1919) 